\title{
A Study on Tray Adhesives Used with Elastomeric Impression Materials and Different Types of Trays
}

\author{
Shruti Sahay ${ }^{1}$, Vahini Reddy ${ }^{2}$ and K Chandrasekharan Nair ${ }^{3 *}$ \\ ${ }^{1}$ Dental Specialist, Sai Dental Care, Bannerghatta Road, Bangalore, Karnataka, \\ India \\ ${ }^{2}$ Former Professor of Prosthodontics, AECS Maaruti College of Dental Sciences, \\ Bangalore, India \\ ${ }^{3}$ Professor Emeritus, Department of Prosthodontics, Sri Sankara Dental College, \\ Akathumuri, Thiruvananthapuram, Kerala, India
}

*Corresponding Author: K Chandrasekharan Nair, Professor Emeritus, Department of Prosthodontics, Sri Sankara Dental College, Akathumuri, Thiruvananthapuram, Kerala, India.

\begin{abstract}
Objectives: Tray adhesives used with putty consistency addition Silicone and condensation silicone elastomeric impression materials on different types of trays viz. metallic trays, perforated metallic trays, plastic trays and perforated plastic trays. Comparison of tensile bond strength of two brands of tray adhesives viz. Coltene and Zhermack when used with addition curing and condensation curing putty consistency impression materials.

Materials and Methods: Perforated and non-perforated metallic and plastic discs measuring Disc specimens measuring 64mm $\mathrm{x}$ $8 \mathrm{~mm}$. Tray adhesive was applied on the tray and allowed to dry for 10 minutes. Uniform thickness of impression material in thickness of $4 \mathrm{~mm}$ was loaded on to the tray. This assembly was attached to the universal testing machine material and at a cross head speed of $1 \mathrm{~mm} / \mathrm{sec}$ it was pulled until separation occurred. The thrust area of the study was to find out the tensile bond strength of tray adhesives used with putty consistency addition silicone elastomeric impression material and putty consistency condensation silicone elastomeric impression material with different types of impression trays. The test parameters selected for the study were the strength of adhesion betweeni) the two brands of elastomeric impression material used in the study - Coltene vs. Zhermack (ii) the two consistencies of the impression materials - Addition vs. Condensation (iii)Metal tray vs. Plastic tray and (iv)Perforated vs. Nonperforated trays, which comibination is better. Data was statistically analyzed using ANOVA test.

Results: The mean tensile bond strength for metal tray was found as $0.99 \mathrm{MPa}$ while plastic trays showed higher bond strength of 1.64 MPa. Perforated tray and nonperforated tray exhibited mean tensile bond strength as 1.29MPa and 1.34MPa respectively. When comparisons were done for tray adhesives the mean retention strength yielded by coltene tray adhesives was $1.34 \mathrm{MPa}$ while zhermack tray adhesive yielded 1.29MPa. When combination of different types of trays with tray adhesives and impression materials were evaluated addition silicone with nonperforated plastic tray with coltene tray adhesive exhibited highest tensile bond strength of (1.91 MPa) while the lowest tensile bond strength was recorded by the use of metal nonperforated tray with condensation silicone impression materials and zhermack tray adhesives (072MPa). The results obtained were statistically significant.

Conclusions: The best combination that would exhibit the high bond strength is non perforated plastic tray with putty consistency additional silicone impression material and Coltene adhesives

Keywords: Tray Adhesive; Elastomeric Impression Material; Impression Trays Viz; Metallic; Non-Metallic; Metallic Perforated and Non-Metallic Perforated; Tensile Bond Strength
\end{abstract}




\section{Introduction}

Any additional description on the role of impressions in prosthodontic practice will be superfluous in the present time. It is evident that prosthodontic restorations are built up on the foundation laid by a good impression. A good impression implies accurately copied details of prepared and unprepared teeth and adjacent tissues. The copied features are to be sustained for a considerable period of time and it is dependent on the properties of the impression material, adequately supported by the impression tray and the successful bond between the tray and the impression material. Many of the non-elastic materials adhered to the impression tray whereas hydrocolloid impression material required mechanical devices. Elastomeric impression materials require tray adhesives to provide an effective bond between the tray and the impression material. The tensile bond strength provided by the adhesive ranged between 1.2 to $3 \mathrm{MPa}$ [1].

Tray adhesives are usually technique sensitive as well as product specific [2,3]. Impression techniques have undergone dramatic changes based on quality criteria and user friendliness. Four decades ago, the combination of custom-made trays and light or regular body elastomers were popular with fixed prosthodontic practice. Later, putty light body combination on stock tray has become popular because of the simplicity and the maintenance of high quality. Effectiveness of tray adhesives has been the subject of study but it was focusing on custom tray materials and different types of tray adhesives. Hence the effectiveness of tray adhesives used between stock tray and putty consistency elastomers has not received much attention. Hence it was thought appropriate to formulate a study to find out the effectiveness of tray adhesives under different variables: brands, composition of putty materials and different types of trays. Virtual impression techniques are slowly becoming popular but impressions with trays are very relevant in our country because of the vastness of the country and the enormous population it has. The present study was taken up in this context with the following objectives

- To find out the tensile bond strength of Tray adhesives used with putty consistency addition silicone and condensation silicone elastomeric impression materials on different types of trays viz. metallic trays, perforated metallic trays, plastic trays and perforated plastic trays.

- Comparison of tensile bond strength of two brands of tray adhesives viz. Coltene and Zhermack when used with addition curing and condensation curing putty consistency impression materials.

\section{Methodology}

Two brands of putty consistency addition silicone impression material - Affinis (Coltene), Elite P\&P (Zhermack), two brands of putty consistency condensation silicone impression material - Speedex (Coltene), Zeta plus (Zhermack) and tray adhesives of specified brands - Coltene adhesive (Coltene), Universal tray adhesive (Zhermack) were selected for the study.

\section{Preparation of specimens}

The specimen consisted of two metallic discs $(64 \times 8 \mathrm{~mm})$ with a central shaft attached to one side of the disc (Figure 1-4). The discs were positioned in a ring containing two shoulder stops so that the discs maintained a uniform space of $4 \mathrm{~mm}$ in between (Figure 5,6 ). The disc-ring assembly was then enclosed in a wooden housing so that the complete assembly could be placed in the hydraulic press. Metallic discs with and without perforations were used to simulate metallic impression trays. To simulate plastic impression trays, perforated and non-perforated plastic discs with similar dimensions were prepared using auto polymerizing acrylic resin. The disc surfaces were coated with tray adhesive according to the manufacturers' instruction. Manipulated putty impression material was then placed between the discs enclosed by the metallic ring and then placed within the wooden housing. This assembly was kept in the hydraulic press and pressure was applied till the discs were seated completely in the ring. This ensured a uniform thickness of $4 \mathrm{~mm}$ for the impression material. This method was a modified version described by Marafie., et al. [4].

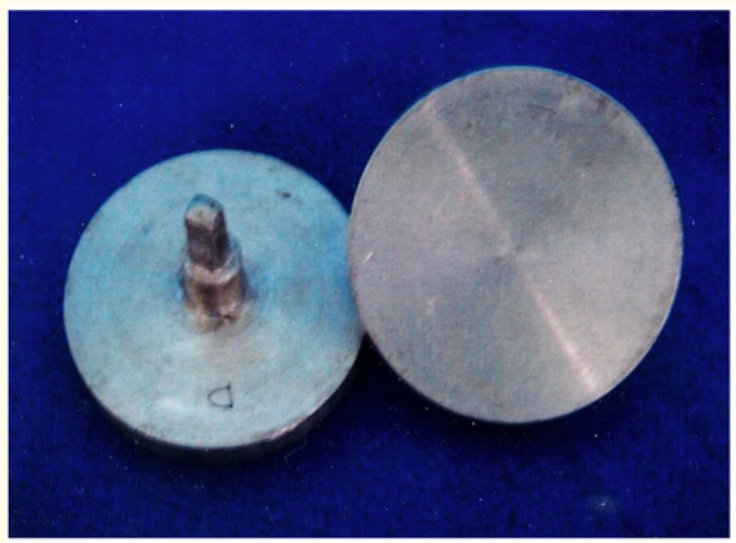

Figure 1: Metallic disc with central shaft representing metal impression tray. 


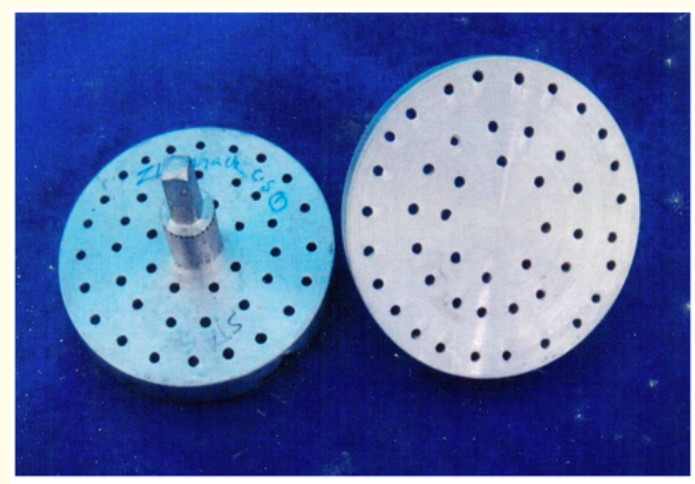

Figure 2: Perforated metallic discs with central shaft representing perforated tray.

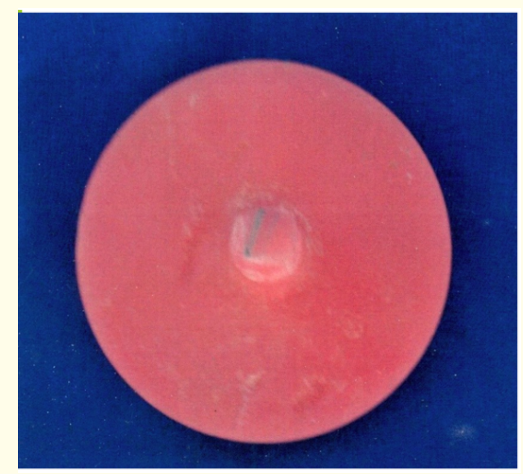

Figure 3: Plastic disc with central shaft representing plastic tray.

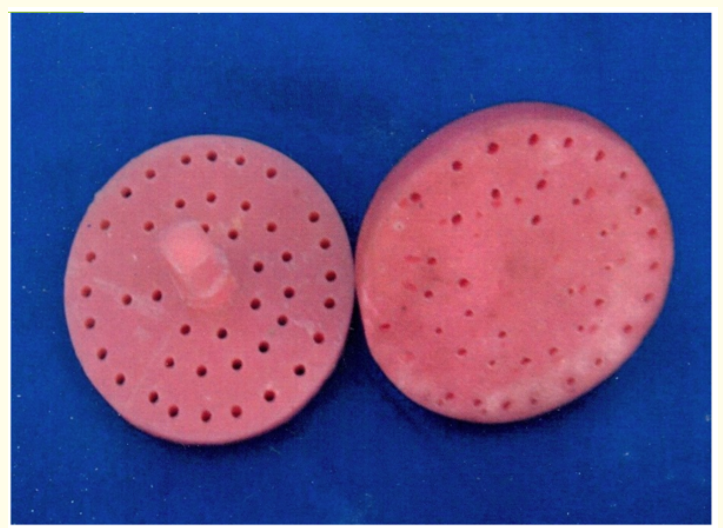

Figure 4: Perforated plastic discs with central shaft representing perforated tray.

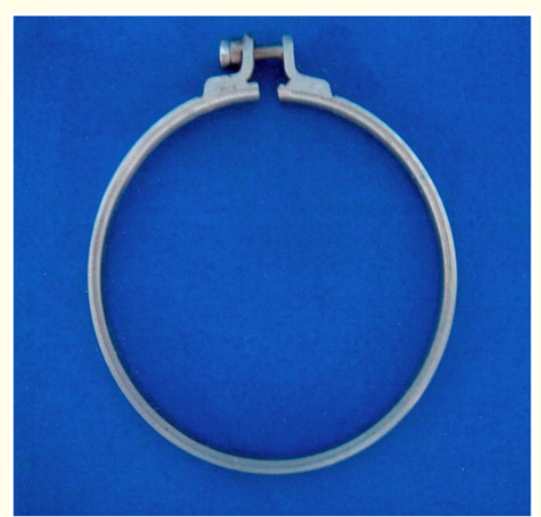

Figure 5: Metal ring with two shoulder stops.

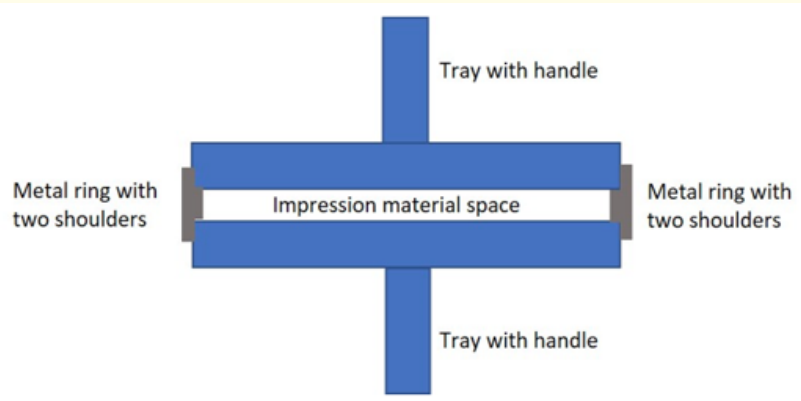

Figure 6: Schematic diagram of the specimen assembly.

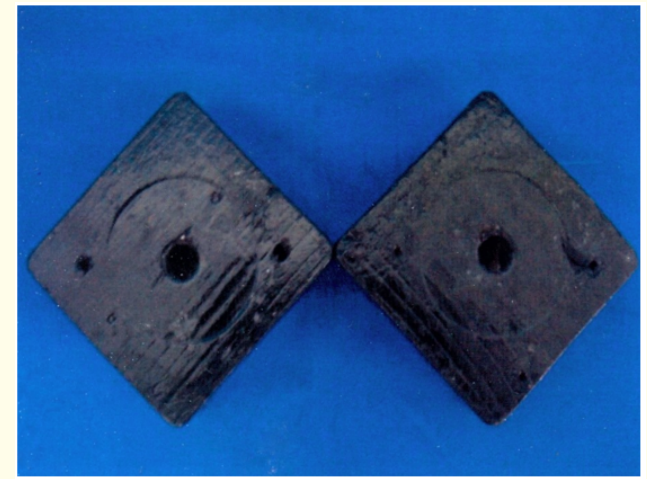

Figure 7: Wooden housing for placing the specimen assembly.

160 specimens were made for testing the tensile bond strength. Distribution of specimens is shown in the flow chart on methodol- 
ogy (Figure 8). The upper shaft of the prepared specimens was attached to the upper member of the universal testing machine and the lower shaft of the specimen was attached to the lower member of the universal testing machine (Figure 9). The retention strength of the tray adhesive was measured by the application of tensile force until the impression material got separated from the trays (Figure 10,11). Tensile load was applied at a constant speed of $1 \mathrm{~mm} / \mathrm{min}$. The results obtained were in mega pascal (MPa). Factorial analysis of variance (ANOVA) was used to analyse the data statistically.

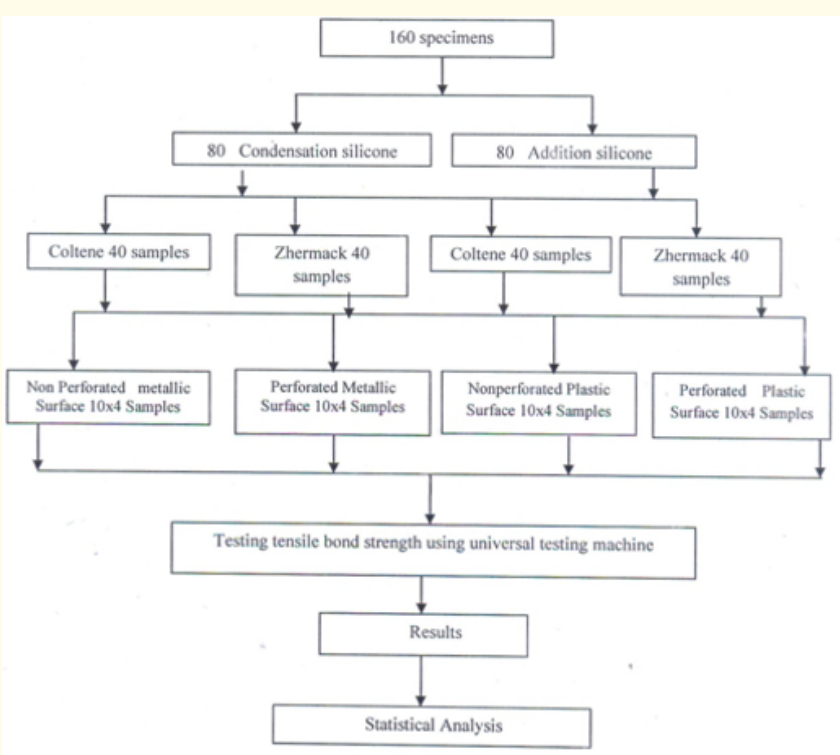

Figure 8: Flow chart on methodology.

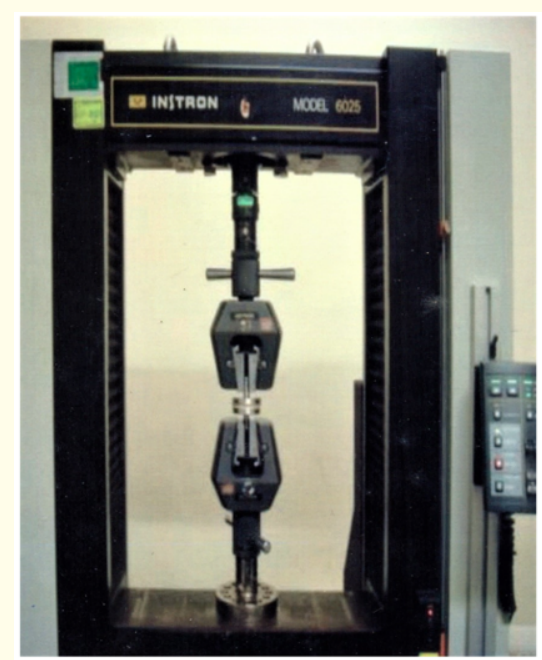

Figure 9: Universal testing machine.

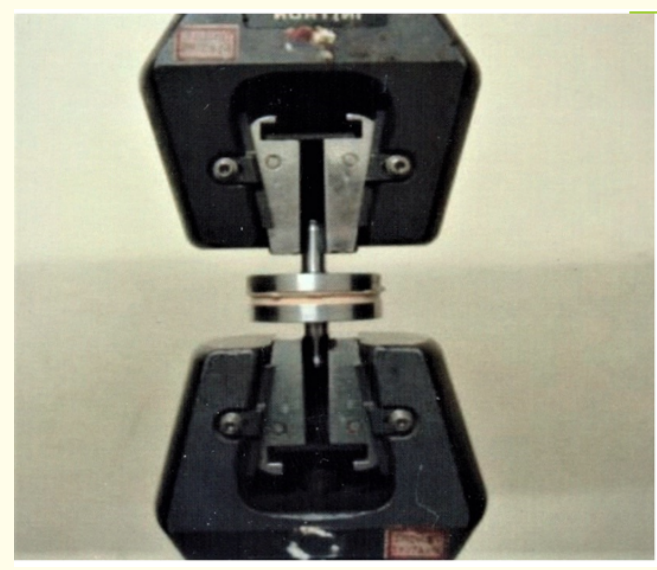

Figure 10: Tensile load applied on the specimen.

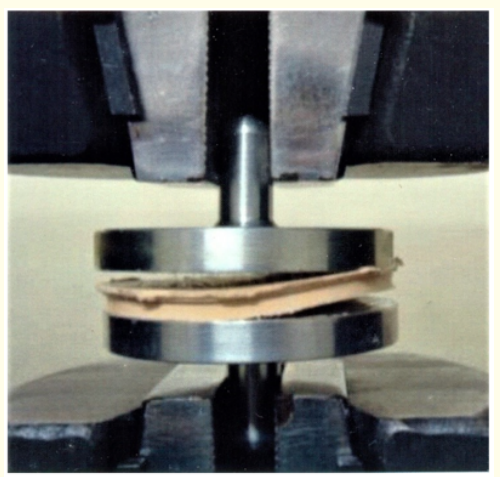

Figure 11: On application of tensile force impression material gets separated from the tray.

\section{Results}

The tensile bond strength (retention strength) under different variables were analysed and the following results were obtained: Between the two trays, plastic tray recorded a higher mean retention strength compared to metal tray and the difference between them was found to be statistically significant ( $P<0.001)$. Nonperforated samples recorded a higher mean retention strength than perforated samples at a statistically significant $(\mathrm{P}<0.001)$ level. Samples with plastic tray recorded a higher mean retention strength compared to metal tray $(\mathrm{P}<0.001)$. Coltene adhesives recorded a higher mean retention strength compared to Zhermack adhesives $(\mathrm{P}<0.001)$. Addition silicone impression materials recorded a higher retention strength than condensation silicone $(\mathrm{P}<$ 0.001). The interaction of various factors and their levels was also found to be statistically significant $(\mathrm{P}<0.05)$. (Table 1,2$)$. The most 
important factor influencing retention strength is the impression tray followed by the impression material, perforation and adhesive respectively. The best combination to have superior bonding be- tween the impression and the tray is to use non perforated plastic tray with addition silicone impression material and Coltene adhesive (Figure 12).

Table 1: Mean retention (Tensile bond) strength obtained with the combination of trays, perforation, adhesives and impression materials: (MPa).

\begin{tabular}{|c|c|c|c|c|c|}
\hline Tray & Perforation & Adhesive & $\begin{array}{c}\text { Impression } \\
\text { Material }\end{array}$ & Mean (MPa) & Std dev \\
\hline Metal & Perforated & Coltene & Cond. silicone & 1.06 & 0.05 \\
\hline , & $”$ & $”$ & Add. silicone & 1.18 & 0.19 \\
\hline$"$ & $”$ & Zhermack & Cond. silicone & 0.79 & 0.04 \\
\hline ", & " & $”$ & Add. silicone & 1.17 & 0.17 \\
\hline, & Non perforated & Coltene & Cond. silicone & 0.99 & 0.05 \\
\hline , & $”$ & ", & Add. silicone & 1.10 & 0.19 \\
\hline " & $"$ & Zhermack & Cond. silicone & 0.72 & 0.07 \\
\hline$"$ & $”$ & " & Add. silicone & 0.89 & 0.05 \\
\hline Plastic & Perforated & Coltene & Cond. silicone & 1.25 & 0.04 \\
\hline ” & $”$ & $"$ & Add. silicone & 1.78 & 0.07 \\
\hline ", & $”$ & Zhermack & Cond. silicone & 1.02 & 0.04 \\
\hline$"$ & $"$ & " & Add. silicone & 2.05 & 0.07 \\
\hline, & Non perforated & Coltene & Cond. silicone & 1.47 & 0.06 \\
\hline$"$ & ", & $"$ & Add. silicone & 1.91 & 0.06 \\
\hline$”$ & ", & Zhermack & Cond. silicone & 1.59 & 0.02 \\
\hline$”$ & $”$ & ” & Add. silicone & 2.07 & 0.05 \\
\hline
\end{tabular}

Table 2: ANOVA table.

\begin{tabular}{|l|c|c|c|c|c|}
\hline Source & df & Sum of squares (SS) & Mean (SS) & F & P-Value \\
\hline Tray & 1 & 17.2261 & 17.2261 & 2057.410 & $<0.001^{*}$ \\
\hline Perforation & 1 & 0.1194 & 0.1194 & 14.260 & $<0.001^{*}$ \\
\hline Adhesive & 1 & 0.1127 & 0.1127 & 13.460 & $<0.001^{*}$ \\
\hline Impression material & 1 & 6.6120 & 6.6120 & 789.710 & $<0.001^{*}$ \\
\hline Tray x Perforation & 1 & 1.2878 & 1.2878 & 153.810 & $<0.001^{*}$ \\
\hline Tray x Adhesive & 1 & 0.7169 & 0.7169 & 85.620 & $<0.001^{*}$ \\
\hline Tray x Impression Material & 1 & 1.8443 & 1.8443 & 220.280 & $<0.001^{*}$ \\
\hline Perforation x Adhesive & 1 & 0.0005 & 0.0005 & 0.050 & $<0.001^{*}$ \\
\hline Perforation x Impression material & 1 & 0.4512 & 0.4512 & 53.890 & $<0.001^{*}$ \\
\hline Adhesive x Impression material & 1 & 0.4748 & 0.4748 & 56.710 & $<0.001^{*}$ \\
\hline Tray x Perforation x Adhesive & 1 & 0.1220 & 0.1220 & 14.570 & $<0.001^{*}$ \\
\hline Tray x Perforation x Impression material & 1 & 0.0982 & 0.0982 & 11.730 & $<0.001^{*}$ \\
\hline Tray x Adhesive x Impression material & 1 & 0.0352 & 0.0352 & 4.200 & $0.042^{*}$ \\
\hline Perforation x Adhesive x Impression material & 1 & 0.2701 & 0.2701 & 32.260 & $<0.001^{*}$ \\
\hline Tray x Perforation x Adhesive x Imp.material & 1 & 0.0439 & 0.0439 & 5.250 & $0.023^{*}$ \\
\hline Error & 144 & 1.2057 & 0.0084 & --- & --- \\
\hline Total & 159 & 30.6208 & --- & --- & --- \\
\hline
\end{tabular}




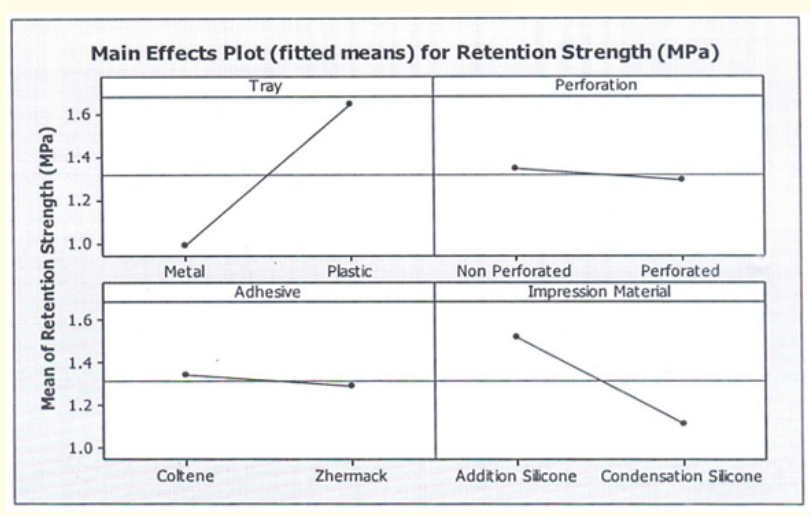

Figure 12: Main Effects Plot- showing the mean values recorded at different levels of each factor.

\section{Discussion}

The present study was conducted to determine the retention strength of tray adhesives used with putty consistency addition silicone elastomeric impression materials and condensation silicone elastomeric impression materials when used with metallic, nonmetallic, perforated and nonperforated trays. The specimens consisted of two discs (64 x 8mm) with a central shaft attached to one side. The discs could be assembled in a ring containing two shoulder stops so that the discs, maintained a uniform space of $4 \mathrm{~mm}$ in between. Single coat of tray adhesive was applied over the flat surface of the disc and was allowed to dry for 10 minutes. Impression material was loaded on to the discs with thickness of $4 \mathrm{~mm}$ [4]. This assembly was kept in the hydraulic press and pressure was applied till the discs were seated completely in the ring. This ensured a uniform thickness of $4 \mathrm{~mm}$ for the impression material [5].

\section{Trays}

Four different types of specimens were made simulating metallic-perforated, metallic non-perforated, plastic-perforated and plastic non-perforated trays. To simulate perforated trays $2.5 \mathrm{~mm}$ diameter perforations were made on the tray. Results obtained showed that Plastic trays had higher mean retention strength of $1.64 \mathrm{MPa}( \pm 0.36)$ and metal had $0.99 \mathrm{MPa}( \pm 0.20)$. The difference that existed between the two types of trays, was possibly due to the material used for fabricating the impression tray.

Non perforated trays showed higher tensile bond strength than the perforated trays. But it is interesting to note that the perforation did not augment considerably the bonding of the adhesive as anyone could naturally presume. When used with any of the adhesive, non-perforated samples always exhibited a higher retention strength compared to perforated samples. Also, nonperforated samples exhibited a higher mean retention strength compared to perforated samples when used with condensation silicone but it is the reverse in case of addition silicone. However, Wang and Sulong have observed a positive effect of perforations $[5,6]$.

\section{Adhesives}

Two brands of paint on adhesives - Coltene, Zhermack - were used in the present study. Adhesives have a positive role to play in providing bonding for the impression material. Brand specificity of the adhesives as recommended by the manufacturer too has a positive role. Paint on adhesives appear to have superior efficiency than spray type adhesives $[7,8]$.

\section{Impression materials}

In the present study addition silicone exhibited superior bond strength to trays as compared to condensation silicone. Other than the tray, impression material decides the retention strength of impression to trays. Different authors have made similar observations [9].

Considering the different combinations of impression trays, presence of perforations, impression materials and adhesives, the authors have worked out an optimum combination for better results - use of non-perforated plastic tray with addition silicone impression material and Coltene adhesive.

\section{Conclusions}

The following conclusions were drawn from the present study

- Plastic tray recorded a higher mean retention strength compared to metal tray.

- $\quad$ Non-perforated samples recorded a higher mean retention strength when compared to perforated samples.

- $\quad$ Between the two adhesives, Coltene recorded a higher mean retention strength when compared to Zhermack.

- Addition curing silicone recorded a higher mean retention strength than condensation silicone.

- Plastic tray always exhibited a higher mean retention strength than metallic tray irrespective of perforations, brand of adhesives and the type of impression materials. 
- The best combination that would exhibit the high bond strength is non perforated plastic tray with putty consistency additional silicone impression material and Coltene adhesives.

\section{Bibliography}

1. Nicholson J W., et al. "Strength of tray adhesives for elastomeric impression materials". Operative Dentistry 10 (1985): 12-16.

2. Hogans WR and Agar JR. "The bond strength of elastomer tray adhesives to thermoplastic and acrylic resin tray materials". Journal of Prosthetic Dentistry 67 (1992): 541-543.

3. Cho GC., et al. "Tensile bond strength of polyvinyl siloxane impressions bonded to a custom tray as a function of drying time: Part I". Journal of Prosthetic Dentistry 73 (1995): 419-423.

4. Marafie Y., et al. "Retention strength of impression materials to a tray material using different adhesive methods: An in vitro study". Journal of Prosthetic Dentistry 100 (2008): 432-440.

5. Sulong MZA and Setchell DJ. "Properties of the tray adhesive of an addition polymerizing silicone to impression tray materials". Journal of Prosthetic Dentistry 66 (1991): 743-747.

6. Wang RR., et al. "The effect of tray material and surface condition on the shear bond strength of impression materials". Journal of Prosthetic Dentistry 74 (1995): 449-454.

7. Yi M., et al. "Drying time of tray adhesive for adequate tensile bond strength between polyvinylsiloxane impression and tray resin material". Journal of Prosthetic Dentistry 1 (2009): 63-67.

8. Peregrina A., et al. "The effect of different adhesives on vinyl polysiloxane bond strength to two tray materials". Journal of Prosthetic Dentistry 94 (2005): 209-213.

9. Nishigawa G., et al. "Efficacy of tray adhesives for the adhesion of elastomer rubber impression materials to impression modelling plastic for border moulding". Journal of Prosthetic Dentistry 79 (1988): 140-144.

\section{Assets from publication with us}

- Prompt Acknowledgement after receiving the article

- Thorough Double blinded peer review

- Rapid Publication

- Issue of Publication Certificate

- High visibility of your Published work

Website: www.actascientific.com/

Submit Article: www.actascientific.com/submission.php Email us: editor@actascientific.com

Contact us: +919182824667 